\title{
EXPLORATORY INVESTIGATIONS ON METAL-BASED FUELS FOR AIR-BREATHING PROPULSION
}

\section{F. Maggi, S. Colciago, C. Paravan, S. Dossi, and L. Galfetti}

Politecnico di Milano

Department of Aerospace Science and Technology

Space Propulsion Laboratory (SPLab)

34 via La Masa, Milano I-20156, Italy

\begin{abstract}
Air-breathing solid fueled propulsion devices represent rugged, cheap, and rather simple options, out of the ramjet (RJ) category, which can contribute to volume containment and structural weight reduction. In the case of a ducted rocket, a fuel-rich propellant is burned in a primary combustion chamber and part of the oxidizer is taken from the atmosphere to complete the combustion inside a ram burner before exhaust. The use of metal additives contributes to the development of high-energy density materials, featuring better volumetric specific impulse. Metal powders are characterized by high energetic content per unit volume but can feature issues of difficult ignition, generation of condensed combustion products (CCPs), and incomplete combustion. The present work discusses a series of exploratory investigations on aluminum-based pyrolants. Thermochemical analyses, calorimetric investigations, and combustion tests will be considered, looking at improvements introduced by metal addition.
\end{abstract}

\section{NOMENCLATURE}

\section{Symbols}

a Pre-exponent Vieille's law, $\mathrm{mm} / \mathrm{s} / \mathrm{bar}^{n}$

$D_{43} \quad$ Mass-mean diameter, $\mu \mathrm{m}$

$d(50)$ Size of the 50th percentile in the mass-weighted particle size distribution

$g_{0} \quad$ Standard gravity acceleration, $\mathrm{m} / \mathrm{s}^{2}$

$I_{s} \quad$ Gravimetric specific impulse, $\mathrm{s}$

$I_{v} \quad$ Volumetric specific impulse, $\mathrm{kg} \cdot \mathrm{s} / \mathrm{m}^{3}$

$M_{\text {mol }}$ Molar mass, $\mathrm{kg} / \mathrm{mol}$

$n \quad$ Exponent Vieille's law 
$r_{b} \quad$ Burning rate, $\mathrm{mm} / \mathrm{s}$

$R^{2} \quad$ Coefficient of determination

$\mathfrak{R} \quad$ Universal gas constant, $\mathrm{J} /(\mathrm{mol} \cdot \mathrm{K})$

$T_{e} \quad$ Temperature at nozzle exit, $\mathrm{K}$

$T_{0} \quad$ Total temperature in ram burner, $\mathrm{K}$

$V_{\infty} \quad$ Flight velocity, $\mathrm{m} / \mathrm{s}$

$\gamma \quad$ Specific heat ratio

$\Delta h_{f}^{0}$ Enthalphy of formation in standard state

$\rho_{\text {th }} \quad$ Ideal propellant density, $\mathrm{kg} / \mathrm{m}^{3}$

$\Phi \quad$ Air-to-propellant mass ratio

\section{Acronyms}

AP Ammonium perchlorate

CCP Condensed combustion product

CEA Chemical equilibrium with applications

CPS Combination propulsion systems

FAP Fine fraction of AP

HTPB Hydroxyl-terminated polybutadiene

PBAN Polybutadiene acrylonitrile

RJ Ramjet

\section{INTRODUCTION}

In some high-speed and launch propulsion applications, air-breathing technology can replace rockets, with consistent gains of payload mass and cost. Currently, there are efforts underway to develop reusable launch vehicles using more fuelefficient engine cycles during part of the ascent orbit and exploiting two or more separate propulsion systems that operate independently. An example of these devices, called combination propulsion systems (CPS), is the rocket RJ configuration which uses a booster to achieve the initial acceleration to speeds capable of sustaining RJ operation. These solutions combine the space-based performance of traditional rockets with the atmospheric performance of $\mathrm{RJ} /$ scramjet engines. The use of atmospheric oxygen ensures oxidizer mass savings, leading to incremented payload mass fractions. Although not straightforward for technological reasons (e.g., high stagnation temperature, performance variation with flight conditions, or thrust control), some past studies have drafted the possibility to develop multistage launch applications based on air-breathing units [1]. Currently, airborne launch options for small payloads are either under development or operative, conferring possible gains to atmospheric or suborbital missions $[2,3]$. Moreover, recurrent cost reduction is envisaged by implementing 
Table 1 Takeoff weight fraction breakdown for airbreathing and rocket applications [4]

\begin{tabular}{lcccc}
\hline \multicolumn{1}{c}{ System } & Payload & Structure & Fuel & Oxidizer \\
\hline Air-breathing & 15 & 55 & 30 & 0 \\
Rocket & 4 & 7 & 24 & 65 \\
\hline
\end{tabular}

reusable propulsion unit. Weight breakdown at takeoff for generic air-breathing and rocket systems is reported in Table 1, as suggested by Heiser and Pratt [4].

Among the air-breathing propulsion options, the configuration of a ducted rocket represents a compromise. The unit is fueled with an oxidizer-deficient solid propellant (pyrolant) which burns in a gas generator. The combustion products are then mixed in a secondary combustion chamber (ram burner), where oxidation is sustained by atmospheric air, before nozzle exhaust. This configuration grants higher gravimetric specific impulse than a solid rocket unit but lower than a pure RJ. However, it maintains a higher degree of simplicity with respect to a liquid-fueled propulsion system, reaching interesting level of specific thrust.

The use of energetic ingredients for increment of gravimetric specific impulse potentially offers significant mission advantages, including missile range capability (5 to 1 increase according to King [5]), reduced vehicle weight, higher velocities, and/or lower time-to-target values. Metals supplying high combustion heat per unit mass are exploited to generate high energy-density propellants. Atmospheric propulsion units can also take advantage of incremented volumetric specific impulse, granting more compact design solutions and reduced drag. Among the others, beryllium (not used for toxicity reasons), boron, aluminum, magnesium, titanium, and zirconium are considered in the competent literature [5-9]. Some of these metals are difficult to ignite and efficiently burn inside the rocket, leading to potential losses due to exhaust of partially oxidized products. This work reports an exploratory investigation performed on some oxidizer-lean propellants, based on ammonium perchlorate (AP), hydroxyl-terminated polybutadiene (HTPB), and aluminum. This kind of pyrolants represent a class of fuel-rich propellants used for ducted rockets but can feature a difficult combustion. On one side, the use of an inert binder limits the decomposition capability of the propellant bulk, once the AP is progressively reduced. On the other hand, aluminum is a metal featuring high heat of combustion $(16.4 \mathrm{MJ} / \mathrm{kg})$ but can agglomerate at the burning surface.

\section{IDEAL PERFORMANCE ANALYSIS}

Ideal performance computation has been conducted using thermochemistry. Both primary combustion chamber and ram burner are assumed subsonic, ex- 
erting stagnation properties and equilibrium reaction chemistry. NASA CEA (Chemical Equilibrium with Applications) code was used for these evaluations [10]. In this respect, computations assumed thermochemical properties at the standard state and initial condition of 300-kelvin temperature for propellant ingredients. The brute formula and the relevant HTPB formation enthalpy $\left(\mathrm{C}_{7.075} \mathrm{H}_{10.65} \mathrm{O}_{0.223} \mathrm{~N}_{0.063}, \Delta h_{f}^{0}=-58 \mathrm{~kJ} / \mathrm{mol}\right)$ were recovered from [8]. Total temperature of ram air referred to the respective flight level and Mach number. Nozzle expansion was computed using hypotheses of frozen chemistry model and calorically perfect gas. Inlet air conditions were evaluated according to a simplified mission profile featuring constant dynamic pressure of $95 \mathrm{kPa}$. This is referred by the competent literature as an admissible ceiling value for missiles and rockets [2]. The inlet was adiabatic, accounting for actual pressure recovery according to the MIL-SPEC-5007D [11]. Beginning of takeover speed and limit of hypersonic flight were considered (Table 2).

On the basis of the aforementioned hypotheses, the specific impulse formula for an air-breathing unit with optimal nozzle under chemically frozen expansion process is reported:

$$
I_{s}=\frac{\Phi+1}{g_{0}} \sqrt{\frac{2 \gamma}{\gamma-1} \frac{\Re}{M_{\mathrm{mol}}} T_{0}\left(1-\frac{T_{e}}{T_{0}}\right)}-\frac{\Phi V_{\infty}}{g_{0}} .
$$

Table 2 Selected conditions for ideal performance evaluation

\begin{tabular}{ccccc}
\hline Id. & \multirow{2}{*}{ Mach } & $\begin{array}{c}\text { Altitude, } \\
\mathrm{m}\end{array}$ & $\begin{array}{c}\text { Total pressure } \\
\text { in combustion chamber, bar }\end{array}$ & $\begin{array}{c}\text { Total temperature, } \\
\mathrm{K}\end{array}$ \\
\hline $\mathrm{A}$ & 1.23 & 1000 & 2.03 & 367 \\
$\mathrm{~B}$ & 6.00 & 22400 & 20.98 & 1806 \\
\hline
\end{tabular}

Table 3 Formulations used in performance analysis

\begin{tabular}{lccc}
\hline \multicolumn{1}{c}{ Label } & AP, \%(wt.) & HTPB, \%(wt.) & Fuel, \%(wt.) \\
\hline AP30, ratio 0.30 & 30 & 16 & 54 \\
AP30, ratio 0.45 & 30 & 22 & 48 \\
AP30, ratio 0.60 & 30 & 26 & 44 \\
AP30, ratio 0.75 & 30 & 30 & 40 \\
AP40, ratio 0.30 & 40 & 14 & 46 \\
AP40, ratio 0.45 & 40 & 19 & 41 \\
AP40, ratio 0.60 & 40 & 22 & 38 \\
AP40, ratio 0.75 & 40 & 26 & 34 \\
AP40, Gany [3] & 40 & 10 & 50 \\
AP25, Davenas [12] & 25 & 25 & 50 \\
AP50 & 50 & 14 & 36 \\
\hline
\end{tabular}


Here, the parameter $\Phi$ represents the air-to-propellant mass ratio; $\gamma$ is the specific heat ratio; $T_{0}$ is the total equilibrium temperature in the ram burner; $T_{e}$ is the static temperature at nozzle exit; $M_{\mathrm{mol}}$ is the molar mass of the equilibrium chemical mixture; $V_{\infty}$ is the flight velocity; $g_{0}$ is the standard gravity; and $\mathfrak{R}$ is the universal gas constant. Formulations selected for analysis derive from typical AP/Al/HTPB compositions featuring a progressive decrease of the oxidizer content. Different aluminum-to-binder ratios have been considered (Table 3$)$.

Data for the gravimetric and the volumetric specific impulses, evaluated for the two reference conditions, are reported in Figs. 1 and 2, respectively. From an

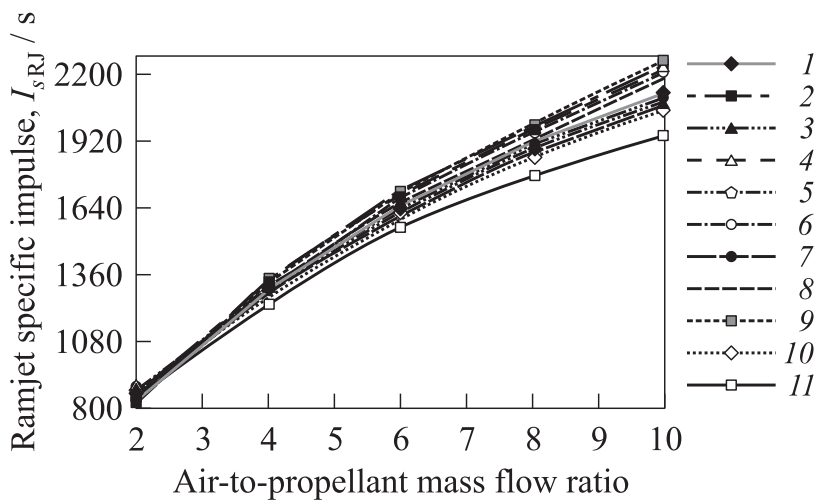

(a)

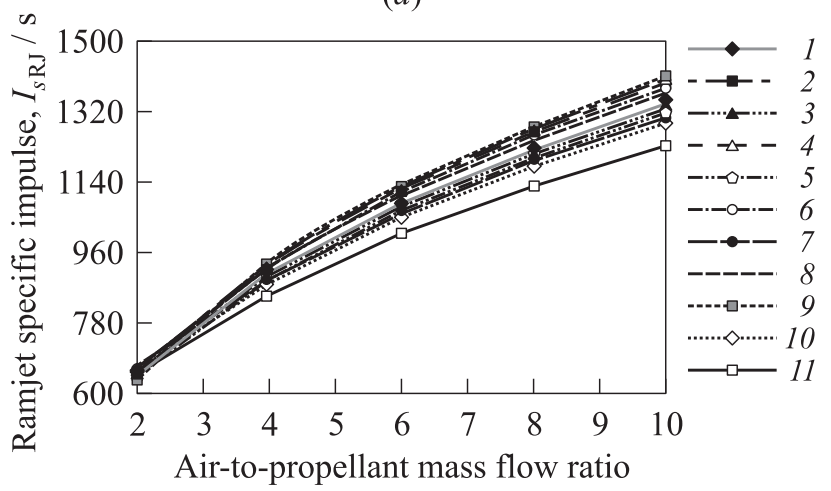

(b)

Figure 1 Gravimetric specific impulse for RJ-kind applications at operating conditions $\mathrm{A}(a)$ and $\mathrm{B}(b)$ (see Table 1$): 1$ - AP40, ratio 0.75; 2 - AP30, ratio 0.75; 3 - AP40, ratio $0.60 ; 4-\mathrm{AP} 30$, ratio $0.60 ; 5-\mathrm{AP} 40$, ratio $0.450 ; 6-\mathrm{AP} 30$, ratio $0.450 ; 7$ - AP40, ratio 0.30; 8 - AP30, ratio 0.30; 9 - AP25, Davenas [12]; $10-$ AP40, Gany [3]; and 11 - AP50 


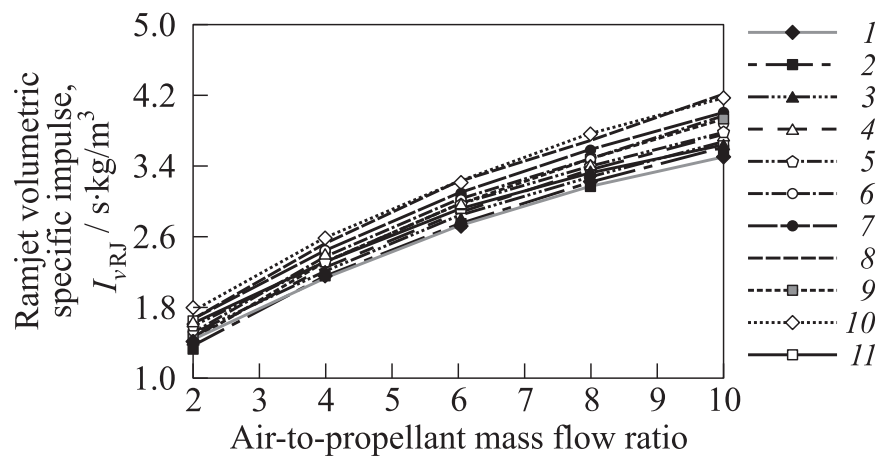

(a)

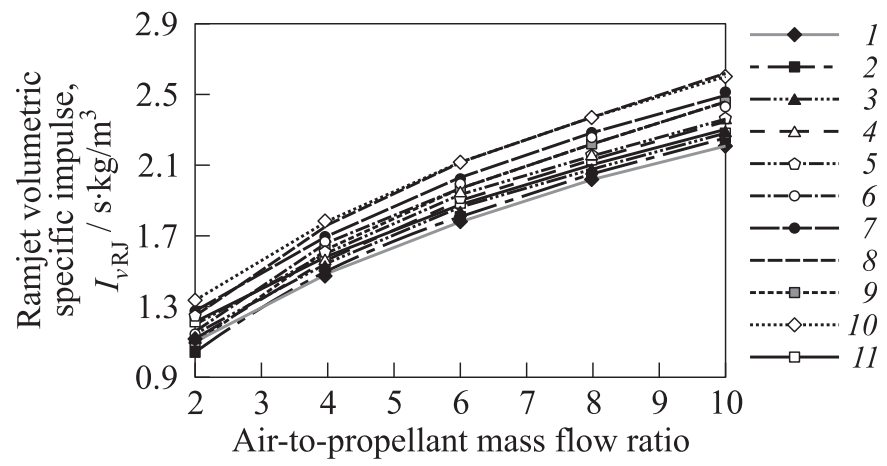

(b)

Figure 2 Volumetric specific impulse for ramjet-kind applications at operating condition A $(a)$ and B $(b)$ (see Table 1): 1 - AP40, ratio 0.75; 2 - AP 30, ratio 0.75; 3 - AP40, ratio $0.60 ; 4-\mathrm{AP} 30$, ratio $0.60 ; 5-\mathrm{AP} 40$, ratio $0.450 ; 6-\mathrm{AP} 30$, ratio $0.450 ; 7$ - AP40, ratio 0.30; 8 - AP30, ratio 0.30; 9 - AP25, Davenas [12]; $10-$ AP40, Gany [3]; and 11 - AP50

ideal viewpoint, curves are monotonically increasing with the air mass flow rate. The reader should be aware that, in these analyses, limits induced by combustor stability or by quality of propellant combustion are not addressed. As expected, propellants containing lower amount of oxidizer have a higher gravimetric specific impulse thanks to an incremented use of atmospheric oxygen.

The increment of the volumetric specific impulse is obtained by those compositions which have a higher metal-to-binder ratio thanks to a progressive increase of pyrolant density. The specific impulse decreases with the increment of flight Mach number due to both negative contribution of ram drag and of incremented air inlet temperature. This second parameter induces more dissociation in the ram burner. The use of a frozen expansion model enables the observation of 
such effect since it does not implement any chemical species recombination during nozzle expansion.

\section{EXPERIMENTAL ANALYSIS}

A series of pyrolants have been selected for experimental analysis. Three different families containing, respectively, $30 \%, 40 \%$, and $50 \%$ by mass of AP, were produced. Inert HTPB binder cured with isocyanate was used. The work targeted self-sustained combustion limit and burning behavior of AP pyrolants enriched with aluminum. The effect of fine oxidizer fraction was assessed as well. Table 4 reports details of experimented formulations, including the amount of the fine oxidizer fraction. Coarse oxidizer was featured by a nominal $d(50)$ of $200 \mu \mathrm{m}$, aluminum had a nominal $d(50)$ of $30 \mu \mathrm{m}$ while the fine AP size was reduced by grinding to obtain $D_{43}=10.5 \mu \mathrm{m}$ (measured by Malvern Mastersizer 2000 laser granulometer with dry dispersion unit Scirocco).

The propellants were compounded using a Labram Resodyn resonant mixer and were tested for burning rate (between 10 and 50 bar) and CCPs up to 40 bar.

Burning tests were accomplished in closed vessels filled with nitrogen atmosphere and pressure-regulated with servovalves. Sample size was $4 \times 4 \times 30 \mathrm{~mm}$. Ignition was obtained with hot-wire technique.

The burning rate measurement was performed using a top-to-bottom combustion configuration inside a windowed vessel. Propellant sides were inhibited using a low molecular weight polymer. Digital video recordings of the tests were used to derive burning rate after proper distance calibration. The postprocessing was performed using the in-house Hydra software.

The collection of combustion residues was performed using a strand burner with quenching pool sketched in Fig. 3. The collecting medium was a halogenbased liquid hydrocarbon. Particles were initially washed with acetone in order

Table 4 Formulations prepared for experimental analysis

\begin{tabular}{lcccc}
\hline \multicolumn{1}{c}{ Id. } & $\begin{array}{c}\text { AP (fine) } \\
\% \text { (wt.) }\end{array}$ & $\begin{array}{c}\text { HTPB, } \\
\% \text { (wt.) }\end{array}$ & $\begin{array}{c}\text { Al, } \\
\%(w t .)\end{array}$ & $\begin{array}{c}\rho_{t h}, \\
\mathrm{~kg} / \mathrm{m}^{3}\end{array}$ \\
\hline AP30, ratio 0.3 & $30(0)$ & 16 & 54 & 1915 \\
AP40(0\% FAP), ratio 0.3 & $40(0)$ & 14 & 46 & 1912 \\
AP40(6\% FAP), ratio 0.3 & $40(6)$ & 14 & 46 & 1912 \\
AP40(12\% FAP), ratio 0.3 & $40(12)$ & 14 & 46 & 1912 \\
AP50(0\% FAP) & $50(0)$ & 14 & 36 & 1862 \\
AP50(6\% FAP) & $50(6)$ & 14 & 36 & 1862 \\
AP50(12\% FAP) & $50(12)$ & 14 & 36 & 1862 \\
\hline
\end{tabular}




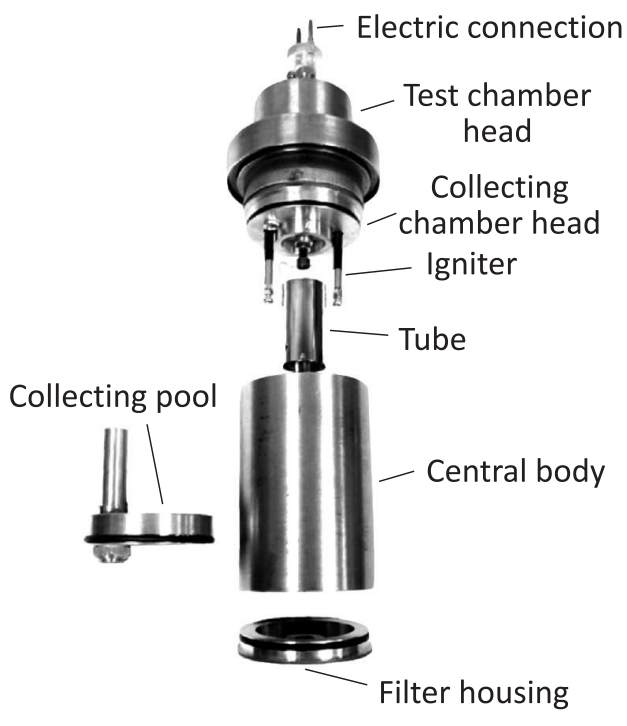

Figure 3 Combustion chamber for CCP collection

to remove the quenching liquid, then dried in oven. Collected materials were treated and measured using laser scattering method (Malvern Mastersizer 2000).

\section{A. AP30 Group}

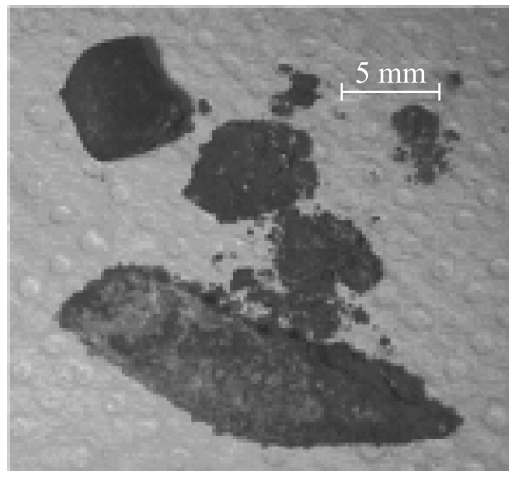

Figure 4 Propellant AP30, ratio 0.3, burning at 50-bar pressure
The combustion of the AP30 composition was highly irregular within the tested range, from 10 to 50 bar. The flame front progressed inside the propellant structure, without destroying the skeleton. Under these conditions, the measurement of the burning rate was meaningless. A residual carbonaceous structure, containing most of unburnt metal particles, was left on the strand holder for all pressures. On the sides of this combustion product, some agglomerates could be observed as a result of the exudate accumulation. The result from 50-bar combustion is reported in Fig. 4. 


\section{B. AP40 Group}

From an ideal viewpoint, this kind of formulation represents a good compromise between oxidizer content and performance. Even though the increment of oxidizer amount was expected to improve combustion quality, the resulting flame was irregular. In this case, the generation of the carbonaceous skeleton trapping both aluminum particles and pyrolysis residues of the binder appeared to be dependent on both pressure and fine AP fraction.

In tested compositions, the skeleton structure tended to disappear gradually once the combustion pressure was above 30 bar (Fig. 5). At 50-bar pressure, the skeleton disappeared but large agglomerates were collected after the burning test. The size of these agglomerates increased with the fine AP content.

The formulation without fine AP showed powdered residues while compositions with $12 \%$ of fine oxidizer demonstrated more vigorous combustion but also incremented size of the CCPs, which could become as large as some millimeters.

For the AP40 formulations, the skeleton structure was influenced by both composition and pressure. Whereas the increment of pressure played in favor of a reduced skeleton structure, the presence of fine oxidizer fostered the generation of large metal agglomerates.
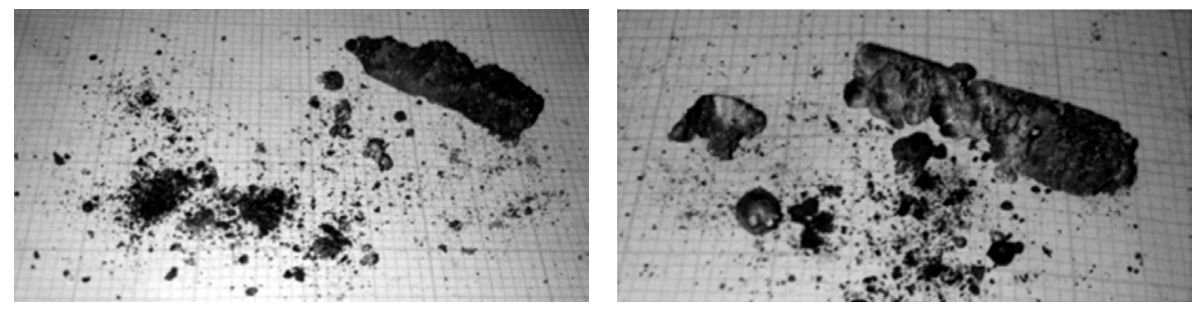

(a)
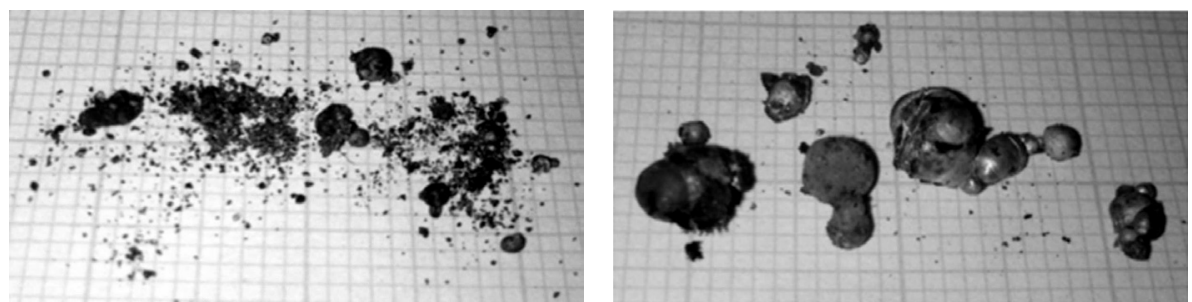

(b)

Figure 5 Combustion residues for AP40, ratio 0.3: (a) 30 bar; (b) 50 bar; left column $-0 \%$ FAP; and right column $-12 \%$ FAP 


\section{AP50 Group}

This family of propellants is characterized by a larger amount of oxidizer, thus implying a worse impact on the weight of AP to carry onboard but also a better behavior in terms of combustion and size of agglomerates. As for the AP40 family, three different alternatives regarding the fine fraction of AP (FAP) content were tested experimentally. Measurement of burning rate and collection of CCPs were possible thanks to the higher quality of combustion.

Figure 6 and Table 5 collect results for burning rate measurements

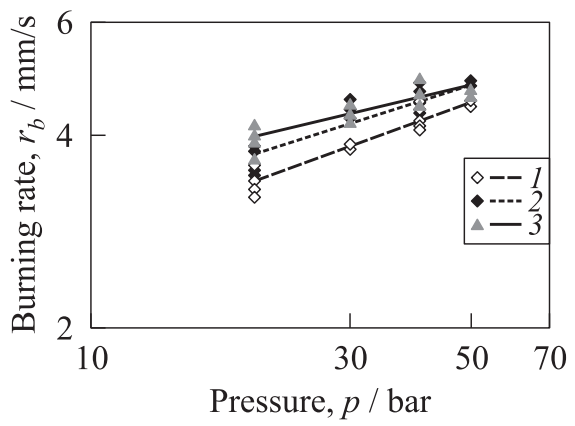

Figure 6 The AP50 burning rate fitting: $1-0 \%$ FAP; $2-6 \%$ FAP; and $3-$ $12 \%$ FAP

between 10 and 50 bar. Although the quality of the combustion was enough to identify a regressing surface, regularity and overall reproducibility were fair testified by the incremented scattering of experimental data and by the reduction of $R^{2}$. Increment of fine AP fraction induced more vigorous flame but also more irregular combustion process leading to incremented data scattering, mainly at higher pressure. Moreover, as fine oxidizer fraction was incremented (reducing the coarse component), the burning rate exponent decreased from 0.31 to 0.20 . A distinctive behavior could be identified for the formulation with $0 \%$ FAP. Rather, a peculiar trend for curves of $6 \%$ and $12 \%$ FAP was not properly obtained due to incremented data scattering, eventually showing the same burning rate at 50 bar.

The analysis of the CCPs was performed at the constant pressure of 40 bar. Powder size distributions are reported in Fig. 7. Each curve derives from the averaging of three samples burned per each tested batch. Table 6 reports the respective $D_{43}$ along with statistical error estimation. CCPs show a bimodal distribution for each tested propellant. The first peak is in the range between 4 and $6 \mu \mathrm{m}$ while the second one is between 330 and $450 \mu \mathrm{m}$. Particles up to

Table 5 Vieille's law for AP50 burning rate measurements

\begin{tabular}{lccc}
\hline \multicolumn{1}{c}{ Propellant } & $a, \mathrm{~mm} / \mathrm{s} / \mathrm{bar}^{n}$ & $n$ & $R^{2}$ \\
\hline AP50 (0\% FAP) & $1.35 \pm 0.10$ & $0.308 \pm 0.022$ & 0.935 \\
AP50 (6\% FAP) & $1.69 \pm 0.18$ & $0.266 \pm 0.030$ & 0.838 \\
AP50 (12\% FAP) & $2.18 \pm 0.22$ & $0.201 \pm 0.029$ & 0.800 \\
\hline
\end{tabular}




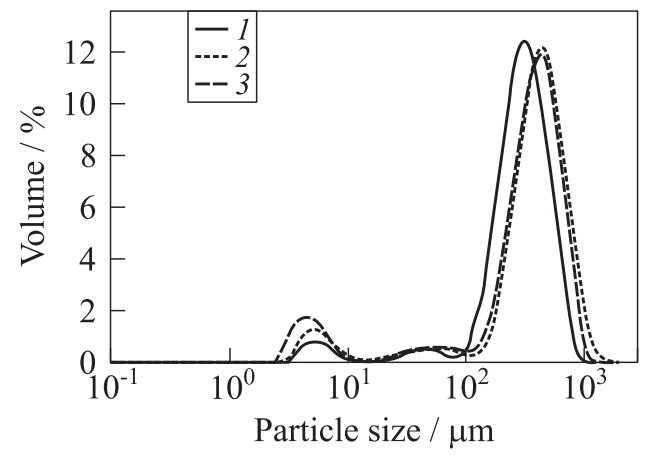

Figure 7 Powder size distribution of CCPs at combustion pressure 40 bar: $1-0 \%$ FAP; $2-12 \%$ FAP; and $3-6 \%$ FAP

about $1-1.5 \mathrm{~mm}$ are present while submicrometric fractions were not identified by the instrumentation. Incremented size of agglomerates was observed for increased FAP content and was more pronounced between propellants AP50 $(0 \%$ FAP $)$ and AP50 (6\% FAP) than among propellant with $6 \%$ and $12 \%$ of FAP particles. Also, in the present case, the level of uncertainty increases with the amount of FAP, confirming the reduced reproducibility of the combustion process.

\section{DISCUSSION}

From results obtained by AP40 and AP50 families, it appears that the amount of fine oxidizer plays a role in the worsening of combustion quality. In both cases, the increase of FAP increments the size of the agglomerates. In AP50 group, levels of $6 \%$ and $12 \%$ of FAP increment the scattering of the burning rate results generating higher dispersion in burning rate data. Competent literature would suggest that increments both of burning rate and of pressure exponent should be observed for such kind of materials. Rather, obtained results show contrasting trends, obtaining an exponent of the Vieille's law around 0.2 for propellants with the highest amount of FAP. Similar results have been reported in a conference paper by Nanda and Ramakrishna for oxidizer-lean formulations but the use of burning rate catalysts by the authors makes the direct comparison 


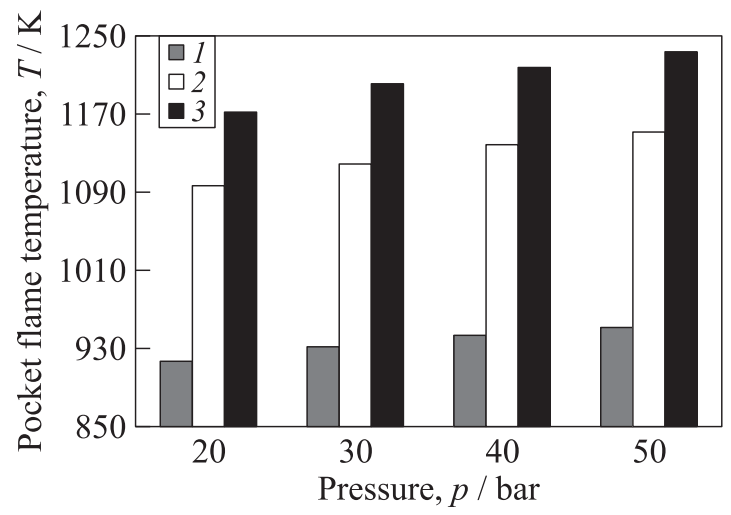

Figure 8 Flame temperature of pocket pseudopropellant

impossible [13]. However, in a report released by the Summerfield's group, the authors underlined that for nonaluminized AP/PBAN (polybutadiene acrylonitrile) propellant, the incremented presence of finer oxidizer fractions can lead to plateau burning or to propellant extinguishment at high pressure [14]. The same report also indicated that there was no influence introduced by the additional presence of aluminum. We should consider that the cited work of Summerfield's group was not considering oxidizer-deficient compositions, which might alter the thermochemical balance at the burning surface.

An influence between fine AP fraction and aluminum can be inferred if the pseudopropellant contained in the pocket structure is targeted, following the concept of Cohen [15] or of Maggi and coauthors [16]. The computed flame temperature, considering binder and FAP as reacting mixture (assuming inert aluminum), are reported in Fig. 8. At 40 bar, the pocket temperature for material without FAP is slightly greater than $940 \mathrm{~K}$, while for propellants AP50 (6\% FAP) and $\mathrm{AP} 50$ (12\% FAP) is, respectively, 1135 and $1118 \mathrm{~K}$, above the melting point of the metal. It is evident from the bar plot that the larger increase is obtained by passing from $0 \%$ to $6 \%$ of FAP, while the growth is limited if the fine fraction is doubled from $6 \%$ to $12 \%$. Similar trend can be noted also looking at results in terms of CCP dimensions. There is a substantial increase of $D_{43}$ between AP50 (0\% FAP) and AP50 (6\% FAP) while the difference between AP50 (6\% FAP) and AP50 (12\% FAP) is not remarkable.

It can be inferred that the increasing size of agglomerates with FAP content is the result of two concurrent processes, which are, respectively, the local surface temperature and the burning rate. The increase of local surface temperature of the pocket, mostly driven by reactivity of fine AP and binder, may favor the sintering of aluminum, leading to large particles. At the same time, the burning rate is increased by the presence of FAP, reducing the residence time of metal 
particles. The resulting CCPs represent a compromise between these concurrent influencing factors. It appears from the aforementioned results that under such experimental conditions, the influence of FAP on the local pocket temperature is stronger than the effect on the burning rate.

\section{CONCLUDING REMARKS}

The present exploratory investigation considered a set of pyrolants for powering ducted rockets. Oxidizer-lean formulations were developed on the basis of standard $\mathrm{AP} / \mathrm{Al} / \mathrm{HTPB}$ propellants. The investigation analyzed the influence of coarse and fine oxidizer fraction, in presence of inert binder and micrometric metal particles. Propellants with oxidizer fractions lower than $40 \%$ by mass created a skeleton structure which resisted to combustion process. Influence on pressure and FAP was observed. Propellants containing $50 \%$ of AP were capable of self-sustained combustion without skeleton structure. With the increment of the fine oxidizer, the burning rate analysis showed a reduction of the pressure exponent and at the same time, an increment of the agglomerate size.

The resulting propellants featured a burning rate level which is about $20 \%$ $40 \%$ lower than a standard AP/Al/HTPB composition for launcher applications but are in line with results reported in the competent literature [5]. However, the decrement of the burning rate pressure exponent limits their applicability in ducted rocket technology. In fact, such value of $n$ is suitable for systems where propellant mass flow rate must be kept constant or within a limited interval (such as in fixed fuel-flow ducted rockets) while are less suitable for nonchoked solid RJs, where propellant throttling capability is important for ram burner combustion at different Mach and flight levels. The presence of large agglomerates discourages the use with variable-flow ducted rockets since the pintle located in the primary combustion chamber may be damaged or clogged.

For the future, burn-rate modifiers, boron-based compounds, and nanometal particles can be tested to improve the behavior of the metallic fuel. On the other hand, other inert/active binders might be of interest, such as GAP (glycidyl azide polymer) or PPG (polypropylene glycol), for the reduction of metal agglomeration process. The tuning of the agglomerate size distribution should be a compromise between residence time needed for combustion and flame stabilization granted by aerodynamic effect of large particles.

\section{REFERENCES}

1. Schöttle, U.M., H. Grallert, and F.A. Hewitt. 1989. Advanced air-breathing propulsion concepts for winged launch vehicles. Acta Astronaut. 20:117-129. 
2. Schade, C., and M. Mosier. 1994. The Pegasus launch vehicle: New capabilities and the future. AIAA Paper No. 1994-1172.

3. Socher, A., and A. Gany. 2008. Investigation of combined air-breathing/rocket propulsion for air launch of microsatellites from a combat aircraft. AIAA Paper No. 2008-5003.

4. Heiser, W.H., D. T. Pratt, D. D. Daley, and U.B. Mehta. 1994. Hypersonic airbreathing propulsion. AIAA education ser. Washington, DC: AIAA. 594 p.

5. King, M. K. 1982. Ignition and combustion of boron particles and clouds. J. Spacecraft Rockets 19(4):294-306.

6. Kubota, N., and T. Kuwahara. 1991. Combustion of energetic fuel for ducted rockets (i). Propell. Explos. Pyrot. 16(2):51-54.

7. Limage, C. R. 1996. Solid fuel ducted rockets for ramjet/scramjet missile applications. AIAA Paper No. 1996-2916.

8. Kubota, N. 2007. Ducted rocket propulsion. Propellants and explosives: Thermochemical aspects of combustion. 2nd ed. Tokio, Japan: John Wiley \& Sons. Ch. 15. P. 439-468.

9. Besser, H. L. 2008. History of ducted rocket development at Bayern-Chemie. AIAA Paper No. 2008-5261.

10. Gordon, S., and B. McBride. 1996. Computer program for calculation of complex chemical equilibrium compositions and applications. NASA RP 1311.

11. Military specification. 1973. Engine, aircraft, turbojet and turbofan, general specification for. MIL-E-5007D. Military Specifications and Standards. DOD, USA.

12. Perut, C. 1993. Propellants for integral rocket ramjet systems. Solid rocket propulsion technology. Ed. A. Davenas. 1st ed. Tarry-town, NY, USA: Pergamon Press. Ch. 12. 525-552.

13. Nanda, J. K., and P. A. Ramakrishna. 2013. Development of AP/HTPB based fuel rich propellant for solid propellant ramjet. AIAA Paper No. 2013-4171.

14. Hall, K. P., E. K. Bastress, and M. Summerfield. 1961. Burning rate control factors in solid propellants. 10th Quarterly Technical Summary Report. Department of the Navy, Office of Naval Research, DTIC No. A952071.

15. Cohen, N.S. 1983. A pocket model for aluminum agglomeration in composite propellants. AIAA J. 21(5):720-725.

16. Maggi, F., L. T. DeLuca, and A. Bandera. 2015. Pocket model for aluminum agglomeration based on propellant microstructure. AIAA J. 53(11):3395-3403. 